\title{
Ocorrência de anticorpos anti-Toxoplasma gondii em ovinos da região de Londrina no Estado do Paraná ${ }^{1}$
}

\section{Occurrence of antibodies to Toxoplasma gondii in sheep from the Londrina Region of the Paraná State, Brazil}

\author{
Liza Ogawa²; Italmar Teodorico Navarro ${ }^{3 *}$; Roberta Lemos Freire ${ }^{3}$; \\ Rosângela Claret de Oliveira' ${ }^{4}$; Odilon Vidotto ${ }^{3}$
}

\begin{abstract}
Resumo
Amostras de 339 soros de ovinos da microrregião de Londrina no Estado do Paraná, foram analisadas através da imunofluorescência indireta para pesquisa de anticorpos anti-Toxoplasma gondii (IFI-IgG), adotando-se como ponto de corte a diluição 1:64. Foram observados 185 (54,6\%) ovinos sororeagentes ao T. gondii, com títulos variando de 64 a 65.536. Todas as propriedades apresentaram ovinos sororeagentes. Animais com idade igual ou maior a dois anos, apresentaram um maior número de sororeagentes, e não foi observada diferença estatística significativa quanto ao sexo. Não foi possível associar a soropositividade para T. gondii com a presença de gatos domiciliados e/ou errantes, uma vez que foi constatada a presença desses animais em todas as propriedades. A partir dos dados obtidos neste estudo, conclui-se que a toxoplasmose está presente no rebanho ovino da microrregião de Londrina no Estado do Paraná.
\end{abstract}

Palavras-chave: Prevalência, Toxoplasma gondii, imunofluorescência indireta, ovinos, anticorpos.

\begin{abstract}
Three hundred and thirty nine serum samples were taken from sheep from Londrina region of the Paraná state, Brazil. Samples were analyzed by indirect immunofluorescence assay (IFA) for the detection of anti-Toxoplasma gondii IgG antibodies. Titers higher or equal to 64 were considered positives. One hundred and eighty five $(54,6 \%)$ of the 339 samples tested were seropositive, with titres ranging from 64 to 65.536. All farms had positives animals. There was a statistical significant difference between seroprevalence to $T$. gondii and age. No significant difference was observed in the association between seropreva Londrina region of the Paraná state, Brazil. Samples were analyzed by indirect immunofluorescence assay (IFA) for the detection of anti-Toxoplasma gondii IgG antibodies. Titers higher or equal to 64 were considered positives. One hundred and eighty five $(54,6 \%)$ of the 339 samples tested were seropositive, with titres ranging from 64 to 65.536 . All farms had positives animals. There was a statistical significant difference between seroprevalence to $T$. gondii and age. No significant difference was observed in the association between seroprevalence and sex. It was not possible to associated $T$. gondiiseroprevalenceand presence of housed or stray cats, because these animals were present in all farms. The present work showed that $T$. gondii has a wide distribution in sheep from this region.

Key words: Prevalence, Toxoplasma gondii., sheep, indirect immunofluorescence assay, antibodies.
\end{abstract}

\footnotetext{
Projeto financiado pela CPG-UEL/CNPq/CAPES

Mestranda do curso de Sanidade Animal da Universidade Estadual de Londrina (UEL)

3 Docente do Departamento de Medicina Veterinária Preventina-UEL. UEL/CCA/DMVP, Caixa Postal 6001, CEP 86051-970, Londrina-PR. E-mail: italmar@uel.br *Autor para correspondência

${ }^{4}$ Residente do Depto. de Med. Vet. Preventiva

* Autor para correspondência.
} 


\section{Introdução}

A toxoplasmose é uma zoonose de caráter cosmopolita, causada pelo Toxoplasma gondii. É um coccídio intestinal de felídeos, que tem como principal hospedeiro definitivo o gato doméstico, sendo o principal disseminador do parasito no meio ambiente.

A primeira descrição do T. gondii em ovinos foi em 1942 por Olafson e Monlux, e desde então, trabalhos demonstraram a importância econômica da infecção toxoplásmica em ovinos como causa de abortos e natimortos (DUBEY et al., 1981; MUNDAY et al., 1987; FREYRE et al., 1997), e na Saúde Pública, considerando o seu aspecto zoonótico (GUPTA et al., 1985; GARCIA et al., 1995; CHAPLIN; SCHMID; SENSTERSEISER, 1995; CHAPLIN, 1997).

Dubey (1986) estabelece três vias primárias de transmissão do T. gondii: congênita, carnivorismo e fecal-oral. A infecção nos ovinos ocorre, principalmente, através da ingestão de oocistos presentes nos alimentos (pastos e ração) e solo contaminados (PLANT et al., 1974; COUTINHO et al., 1982). Clinicamente a toxoplasmose em ovinos é assintomática, porém em ovelhas não imunes que adquirem a infecção durante a gestação, podem desenvolver os distúrbios reprodutivos causados pelo T. gondii, levando a perdas econômicas consideráveis. Após um período de doença aguda, o $T$. gondii desenvolve a forma cística em músculos, cérebro e outros órgãos (JACOBS, 1960; DUBEY et al., 1980, 1993). Essa forma evolutiva do parasito constitui a principal fonte de infecção para o homem, que pode se infectar através da ingestão de carne ou vísceras cruas ou mal cozidas contendo cistos do T. gondii (VIDOTTO et al., 1990; NAVARRO et al., 1992).

Estudos sorológicos sobre a freqüência de anticorpos anti-T. gondii, comprovam a disseminação da toxoplasmose em ovinos, com porcentagens de sororeagentes que variam de 3\% a 92\% (TENTER et al., 2000).

O presente trabalho tem o objetivo de determinar, através da imunofluorescência indireta, a ocorrência da infecção pelo T. gondii em ovinos da microrregião de Londrina no Estado do Paraná.

\section{Material e métodos}

Foram colhidas 339 amostras de sangue de ovinos em sete propriedades da microrregião de Londrina no norte do Estado do Paraná, e para cada uma das amostras era acompanhado de uma ficha epidemiológica dos animais e da propriedade. Esta microrregião compreende os municípios de Londrina, Cambé, Rolândia, Ibiporã e Arapongas; está localizada entre latitude $23^{\circ}$ sul e longitude $51^{\circ}$ oeste de Greenwich; possui clima subtropical úmido mesotérmico, com temperatura média de $21^{\circ} \mathrm{C}$; e apresenta população média de ovinos estimada de 9701 cabeças. Após a retração do coágulo, os soros foram aliquotados, identificados e mantidos a temperatura de $-18^{\circ} \mathrm{C}$ até a realização do teste sorológico.

As amostras foram analisadas através da técnica de imunofluorescência indireta (IFI), conforme Camargo (1974), com a utilização do conjugado antiIgG ovino ${ }^{5}$, previamente padronizado na diluição 1:100. Foram consideradas positivas as reações com título igual ou maior que 64 (RIEMANN; WILLADSAEN; BERRY, 1977).

Foi realizado como tratamento estatístico ${ }^{6}$ o teste de qui-quadrado $\left(\chi^{2}\right)$, com nível de significância de $5 \%$, para verificar possíveis diferenças em relação ao sexo (machos e fêmeas) e faixa etária (até 2 anos, e igual ou maior a 2 anos).

\section{Resultados e Discussão}

Pela avaliação das fichas epidemiológicas, permitiu verificar que em todas as propriedades o tipo de criação foi o semi-extensivo; a alimentação dos animais testados era basicamente composta de pastagens de diversos tipos; a ração era fabricada na propriedade, e a criação dos ovinos tinha finalidade

\footnotetext{
${ }^{5}$ Sigma Chemical

${ }^{6}$ Programa Estatístico EPI INFO (versão 6,04, CDC-Atlanta)
} 
de produção mista (carne e lã). Problemas reprodutivos (abortos, natimortos) foram observados em quatro propriedades; e os problemas sanitários mais frequientes foram relacionados com verminose (apesar de todas as propriedades apresentarem controle anti-parasitário) e problema de casco ("footrot"). A presença de gatos e roedores nas residências, pastos, currais, hortas e depósitos de rações, foi comum em todas as propriedades.

Quanto a freqüência do T. gondii pela IFI, encontrou-se $185(54,6 \%)$ sororeagentes e 154 $(45,4 \%)$ não reagentes (Tabela 1$)$. Os resultados, quando comparados a outros levantamentos em ovinos no Estado do Paraná, demonstram equivalências, como os de Freire et al. (1995) e Garcia et al. (1999), que encontraram porcentagens de $47,8 \%$ e $51,8 \%$ de sororeagentes, respectivamente, na região norte, e Romanelli (2002) observou 51,4\% na região sul do Estado, sendo que esta região apresenta uma ovinocultura bastante desenvolvida. Da mesma forma Langoni et al. (1997) relataram 55,1\% em ovinos do Estado de São Paulo.

A alta porcentagem de ovinos sororeagentes ao T. gondii poderia estar relacionada também a contaminação do ambiente com o parasito. Este fato pode ser explicado pela presença de gatos e roedores, num mesmo ambiente de convívio e pela preferência dos ovinos ao consumo de pastagens e gramíneas de porte mais baixo do peri-domicílio, onde a maioria era mantida, o que favorece a possível ingestão de oocistos. Os gatos, presentes em diversos locais nas propriedades e relacionados com o controle de roedores, têm fundamental importância na epidemiologia do $T$. gondii, já que os oocistos eliminados nas fezes dos gatos podem, dependendo das condições ambientais, perdurar por vários meses até anos no meio ambiente (FRENKEL et al., 1975).

Quanto a faixa etária, a análise dos sororeagentes demonstrou diferença estatística significativa $(\mathrm{P}<0,05)$, sendo que a maior porcentagem de sororeagentes ocorreu em animais com idade igual ou maior a dois anos (Tabela 1), independente do sexo e do tipo de alimentação. Estes resultados estão de acordo com os obtidos por Dubey et al. (1986, 1988), e sugerem que os animais adultos estiveram por mais tempo em contato com as possíveis vias de transmissão do $T$. gondii, resultando em maior chance de se infectarem.

A diferença nas porcentagens observadas entre as faixas etárias, com menor número de sororeagentes nos animais com até dois anos de idade e aliado a maior ocorrência de animais com título igual ou maior que 4096 (26\%), é indicativo de infecção recente, sugerindo que a transmissão vertical não é a principal via de transmissão do agente nestes rebanhos em estudo, indicando que a transmissão horizontal é a mais importante neste ecossistema. Freire et al. (1995) também observaram uma maior ocorrência de sororeagentes com títulos de 4096 $(21,4 \%)$, definindo-os como portadores com infecção aguda. Quando confrontados o sexo em relação à faixa etária, foram observadas diferenças significativas $(\mathrm{P}<0,05)$, sendo que as fêmeas com idade igual ou maior a dois anos apresentaram um maior número de sororeagentes (Tabelas 2,3). Silva et al. (1980) observaram nas fêmeas de um a dois anos um maior número de sororeagentes; porém, Huffman et al. (1981) sugeriram que fêmeas de todas as idades possuem a mesma suscetibilidade para a infecção toxoplásmica.

O consumo da carne (crua ou mal cozida) de ovinos e bovinos foi relatado em três propriedades. Apesar de não ter sido pesquisado a presença de cistos teciduais, os títulos de anticorpos de 64 e $256(54,6 \%)$ são indicativos da presença de cistos, tornando a ingestão desta carne uma importante via de transmissão para o homem (DUBEY et al., 1989). Reforça essa afirmativa o surto de toxoplasmose humana descrita por Bonametti et al. (1997) através da ingestão de carne de ovino oriundo de um rebanho com $47 \%$ de animais sororeagentes pela IFI.

A partir dos dados obtidos neste estudo, pode-se concluir que a toxoplasmose está presente no rebanho de ovinos da microrregião de Londrina no 
Estado do Paraná; bem como ovinos na faixa etária igual ou maior a dois anos apresentaram uma maior freqüência de sororeagentes; e machos e fêmeas estão sujeitos ao mesmo risco de infecção. Esses resultados demonstram o potencial risco de transmissão para o ser humano através de sua carne. Assim sendo, é necessário esclarecer e conscientizar a população sobre a importância dessa zoonose e, através de cuidados preventivos introduzidos no manejo, estabelecer um controle da infecção nos animais, principalmente em relação aos gatos domésticos, a fim de diminuir os riscos de transmissão dessa infecção.

Tabela 1. Freqüência de anticorpos anti-Toxoplasma gondii (IFI-IgG) em soros de ovinos da microrregião de Londrina no Estado do Paraná, segundo a faixa etária. Londrina, 2003.

\begin{tabular}{|c|c|c|c|c|c|c|c|c|c|}
\hline \multirow{2}{*}{$\begin{array}{l}\text { Idade } \\
\text { (anos) }\end{array}$} & \multicolumn{6}{|c|}{ Título de anticorpos n (\%) } & \multirow{2}{*}{$\begin{array}{l}\text { Sororea- } \\
\text { gentes }(\%)\end{array}$} & \multirow{2}{*}{$\begin{array}{l}\text { Não reagen- } \\
\text { tes }(\%)\end{array}$} & \multirow[t]{2}{*}{ Total $(\%)$} \\
\hline & 64 & 256 & 1024 & 4096 & 16384 & 65536 & & & \\
\hline $0-2$ & $14(35)$ & $8(20)$ & $10(25)$ & $4(10)$ & $2(5)$ & $2(5)$ & $40(11,8)$ & $53(15,6)$ & $93(27,4)$ \\
\hline & $35(24,1)$ & $44(30,3)$ & $26(18)$ & $16(11)$ & $15(10,3)$ & $9(6,3)$ & $145(42,8)$ & $101(29,8)$ & $246(72,6)$ \\
\hline Total (\%) & $49(26,5)$ & $52(28,1)$ & $36(19,5)$ & $20(10,8)$ & $17(9,2)$ & $11(5,9)$ & $185(54,6)$ & $154(45,4)$ & $339(100)$ \\
\hline
\end{tabular}

$\chi^{2}=6,28$

$\mathrm{P}=0,012$

Tabela 2. Freqüência de anticorpos anti-Toxoplasma gondii (IFI-IgG) em soros de ovinos da microrregião de Londrina no Estado do Paraná, segundo o sexo. Londrina, 2003.

\begin{tabular}{|c|c|c|c|c|c|c|c|c|c|}
\hline \multirow[t]{2}{*}{ Sexo } & \multicolumn{6}{|c|}{ Título de anticorpos $n(\%)$} & \multirow{2}{*}{$\begin{array}{l}\text { Sororea- } \\
\text { gentes }(\%)\end{array}$} & \multirow{2}{*}{$\begin{array}{l}\text { Não reagen- } \\
\text { tes }(\%)\end{array}$} & \multirow{2}{*}{$\begin{array}{l}\text { Total } \\
(\%)\end{array}$} \\
\hline & 64 & 256 & 1024 & 4096 & 16384 & 65536 & & & \\
\hline Fêmeas & $35(24)$ & $40(27,4)$ & $34(23,2)$ & $13(8,9)$ & $16(11)$ & $8(5,5)$ & $146(78,9)$ & $111(72,1)$ & $257(75,8)$ \\
\hline Machos & $14(35,9)$ & $12(30,8)$ & $2(5,1)$ & $7(17,9)$ & $1(2,6)$ & $3(7,7)$ & $39(21,1)$ & $43(27,9)$ & $82(24,2)$ \\
\hline Total (\%) & $49(26,5)$ & $52(28,1)$ & $36(9,5)$ & $20(10,8)$ & $17(9,2)$ & $11(5,9)$ & $185(100)$ & $154(100)$ & 339 (100) \\
\hline
\end{tabular}

$\chi^{2}=1,79$

$\mathrm{P}=0,181$

Tabela 3. Frequiência de anticorpos anti-Toxoplasma gondii (IFI-IgG) em soros de ovinos da microrregião de Londrina no Estado do Paraná, segundo o sexo e faixa etária. Londrina, 2003.

\begin{tabular}{lllllll}
\hline Sexo & \multicolumn{2}{l}{ Fêmeas n (\%) } & Total (\%) & \multicolumn{2}{l}{ Machos n (\%) } & Total (\%) \\
Faixa etária (anos) & $\mathbf{0}-\mathbf{2}$ & $\mathbf{2}$ & & $\mathbf{0}-\mathbf{2}$ & $\mathbf{2}$ & \\
\hline Sororeagentes & $25(17,1)$ & $121(82,9)$ & $\mathbf{1 4 6}(\mathbf{5 6 , 8})$ & $15(38,5)$ & $24(61,5)$ & $\mathbf{3 9}(\mathbf{4 7 , 6 )}$ \\
Não reagentes & $33(29,7)$ & $78(70,3)$ & $\mathbf{1 1 1}(\mathbf{4 3 , 2})$ & $20(46,5)$ & $23(53,5)$ & $\mathbf{4 3}(\mathbf{5 2 , 4})$ \\
Total (\%) & $\mathbf{5 8}(\mathbf{2 2 , 6 )}$ & $\mathbf{1 9 9}(\mathbf{7 7 , 4 )}$ & $\mathbf{2 5 7}(\mathbf{1 0 0 )}$ & $\mathbf{3 5}(\mathbf{4 2 , 7 )}$ & $\mathbf{4 7}(\mathbf{5 7 , 3 )}$ & $\mathbf{8 2}(\mathbf{1 0 0})$ \\
\hline
\end{tabular}

$\begin{array}{ll}\chi^{2}=5,04 & \chi^{2}=0,26 \\ \mathrm{P}=0,002 & \mathrm{P}=0,608\end{array}$




\section{Referências}

BONAMETTI, A. M; PASSOS, J.N; SILVA, E. M. K; MACEDO, Z. S. Surto de toxoplasmose aguda adquirida através da ingestão de carne crua de gado ovino. Revista da Sociedade Brasileira de Medicina Tropical, Rio de Janeiro, v.30, p.21-25, 1997.

CAMARGO, M. E. Introdução às técnicas de Imunofluorescência. Revista Brasileira de Patologia Clínica, São Paulo, v.10, p.143-169, 1974.

CHAPLIN, E. L; SCHMID, V; SENSTERSEISER, L. Incidência de reagentes para Toxoplasma gondii em trabalhadores e alunos no Hospital Clínicas Veterinária UFRGS, RS, Brasil. In: SEMINÁRIO BRASILEIRO DE PARASITOLOGIA VETERINÁRIA, 8., 1995, Campo Grande. Anais... Campo Grande: Colégio Brasileiro de Parasitologia Veterinária, 1995. p.174.

CHAPLIN, E. L.; SANTOS, M. V. A.; BECKER, S. C.; FINGER, G. P.; RODRIGUES, R. J. D.; SILVA, N. R. S.; ARAUJO, F. A. P.; TADEU, C. C.; MENDES, A.; BASSO, F. Levantamento de reagentes a Toxoplasma gondii e Trypanosoma cruzi em soros humanos do Município de Viamão, RS. In: SEMINÁRIO BRASILEIRO DE PARASITOLOGIA VETERINÁRIA, 10., 1997, Itapema. Anais... Itapema: Colégio Brasileiro de Parasitologia Veterinária, 1997. p.337.

COUTINHO, S. G.; LOBO, R.; DUTRA, G. Isolation of Toxoplasma from the soil during an outbreak of toxoplasmosis in a rural area in Brazil. Jounal of Parasitology, Lawrence, v.68, n.5, p.866-868, 1982.

DUBEY, J. P. Toxoplasmosis. Journal of the American Veterinary Medical Association, Schaumburg, v.189, n.2, p.166-170, 1986.

DUBEY, J. P; SHARMA, S. P. Parasitemia and tissue infection in sheep fed Toxoplasma gondii oocysts. Jounal of Parasitology, Lawrence, v.66, n.1, p.111-114, 1980.

DUBEY, J. P.; SCHMITZ, J. A. Abortion associated with toxoplasmosis in sheep in Oregon. Journal of the American Veterinary Medical Association, Schaumburg, v.178, n.7, p.675-678, 1981.

DUBEY, J. P; MILLER, S; POWELL, E.; ANDERSON, W.R. Epizootiologic investigations on a sheep farm with Toxoplasma gondii induced abortions. Journal of the American Veterinary Medical Association, Schaumburg, v.188, p.155-158, 1986.

DUBEY, J. P; WELCOME, F.L. Toxoplasma gondiiinduced abortion in sheep. Journal of the American Veterinary Medical Association, Schaumburg, v.196, n.6, p.697-700, 1988.
DUBEY, J. P; KIRKBRIDE, C .A. Economic and Public Health considerations of congenital toxoplasmosis in lambs. Journal of the American Veterinary Medical Association, Schaumburg, v.195, p.1715-1716, 1989.

DUBEY, J. P.; CARPENTER, J. L. Unidentified Toxoplasmalike tissue cysts in the brains of three cats. Veterinary Parasitology, Netherlands, v.45, p.319-321, 1993.

FREIRE, R. L.; GIRALDI, N.; VIDOTTO, O.; NAVARRO, I. T. Levantamento soroepidemiológico da toxoplasmose em ovinos na região de Londrina-PR. Arquivo Brasileiro de Medicina Veterinaria e Zootecnia, Belo Horizonte, v.47, n.4, p.609-612, 1995.

FREYRE, A; BONINO, J.; FALCÓN, J.; CASTELLS, O.; CORREA, A. The incidence and economic significance of ovine toxoplasmosis in Uruguay. Veterinary Parasitology, Netherlands, v.73, p.13-15, 1997.

FRENKEL, J. K; RUIZ, A; CHINCHILLA, M. Soil survival of Toxoplasma oocysts in Kansas and Costa Rica. American Journal of Tropical Medicine and Hygiene, Northbrook, v.24, p.439-443, 1975.

GARCIA, J. L; NAVARRO, I. T. Levantamento soroepidemiológico da toxoplasmose em moradores da zona rural do Município de Guaraci-Paraná-Brasil. Semina: Ciencias Agrarias, Londrina, v.16, n.1, p.63-67, 1995.

GARCIA, J. L; NAVARRO, I. T.; OGAWA, L.; OLIVEIRA, R. C. Soroprevalência do Toxoplasmas gondii, em suínos, bovinos, ovinos e eqüinos e sua correlação com humanos, felinos e caninos, oriundos de propriedades rurais do norte do Paraná - Brasil. Ciência Rural, v. 29, p. 91-97, 1999.

GUPTA, S. L; CHHABRA, M. B; GAUTAM, P. Toxoplasma prevalence and human occupational groups. International Journal of Zoonoses, Taipei, v.12, n.2, p.143146, jun. 1985.

HUFFMAN, E. M; KIRK, J. H; WINWARD, L.; GORHAM, J. R. Relationship of neonatal mortality in lambs to serologic status of the ewe for Toxoplasma gondii. Journal of the American Veterinary Medical Association, Schaumburg, v.178, n.7, p.679-682, 1981.

JACOBS, J; REMINGTON, J. S; MELTON, M. L. A survey of meat samples from swine, cattle and sheep for the presence of encysted Toxoplasma. Jounal of Parasitology, Lawrence, v.16, n.1, p.23-28, 1960.

LANGONI, H; SILVA, A. V; ROSA, C.; MARINHO, M.; LISTONI, F. J. P. Prevalência de anticorpos antiToxoplasma em soros de ovinos do Estado de São Paulo. In: CONGRESSO BRASILEIRO DE MEDICINA VETERINÁRIA, 25., 1997. Gramado, Anais... Gramado: Sociedade de Veterinária do Rio Grande do Sul, 1997, p.179. 
MUNDAY, B. L; OBENDORF, D. L.; HANDLINGER, J. H.; MASON, R. W. Diagnosis of congenital toxoplasmosis in ovine foetuses. Australian Veterinary Journal, Artamon, v.64, n.9, p.292, 1987.

NAVARRO, I. T; VIDOTTO, O; GIRALDI, N; FREIRE, R. L. Toxoplasma gondii: isolamento de carne e cérebro de suínos. Semina, Londrina, v.13, n.1, p.32-34, 1992.

OLAFSON, P; MONLUX, W. S. Toxoplasma infection in animals. Cornell Veterinarian, Ithaca, v.32, p.176-190, 1942.

PLANT, J. W; RICHARDSON, N; MOYLE, G. G. Toxoplasma infection and abortion in sheep associated with feeding of grain contaminated with cat faeces. Australian Veterinary Journal, Artamon, v.50, p.19-21, 1974.

RIEMANN,H.P; WILLADSAEN, C. M;BERRY,L. J. Survey for Toxoplasma antibodies among sheeps in Western United State. Journal of the American Veterinary Medical Association, Schaumburg, v.171, p.1260-1264, 1977.

ROMANELLI, P. Avaliação soroepidemiológica do Neospora caninum e Toxoplasma gondii em ovinos do municipio de Guarapuava-Parana. 2002 62p. Dissertação (Mestrado em Sanidade Animal)-Universidade Estadual de Londrina, Londrina.
SILVA, N. R. S.; COSTA, A. J.; SOUZA, S. N. G. Prevalência de anticorpos antitoxoplásmicos em ovinos, determinada pela Reação de Imunofluorescência Indireta (RIFI), no Município de São Lourenço do Sul, RS. Arquivos da Faculdade de Veterinaria da UFRGS, Porto Alegre, v.8, p.89-92, 1980.

TENTER, A. M; HECKEROTH, A. R; WEISS, L. M. Toxoplasma gondii: from animals to humans. Veterinary Parasitology, Netherlands, v.30, p.1217-1258, 2000.

VIDOTTO,O.; NAVARRO,I. T.; GIRALDI, N.;FREIRE, R.L.; MITSUKA, R. Estudos epidemiológicos da toxoplasmose em suínos da região de Londrina-PR. Semina: Ciencias Agrarias, Londrina, v.11, n.1, p.29-33, 1990.

ZONTA, J. C.; ARAUJO, F. A. P.; STOBBE, N. S.; CHAPLIN, E. L.; SILVA, N. R. S. Prevalência de anticorpos toxoplásmicos em ovinos de Marau e de Uruguaiana, RS. Arquivos da Faculdade de Veterinária da UFRGS, Porto Alegre, v.15/16, p.59-61, 1987/8. 